\title{
Support for users within an educational or e-learning context
}

\section{Nicola Osborne, Social Media Officer at EDINA}

\section{Introduction}

Learning has often been associated with particular physical spaces, whether formal classrooms or lecture theatres or more informal spaces such as a workshop or studio. However learning spaces have been changing and moving partly or fully online (Brown 2005) leading to new and different learning and teaching experiences.

Emergent technology - from the earliest electronic resources to virtual learning environments (VLEs), communications tools and social media - have enabled a radical shift in how educational space may be defined (Lave \& Wenger 1991), and an increasing blurring of the relationship between learning spaces and the other online spaces a learner may inhabit. Even the most traditional offline course should expect some or many participants to be engaged in recreational use of social mediai.

For me, the net is a wonderful learning network and for some it is a lifeline and for others it is a tether to their boss or a source of harmful misinformation, disinformation, and distraction. Since when is the world starkly divided into either-or alternatives?

Howard Rheingold (quoted in Anderson and Rainie 2010: 13)

The modern learning experience takes place in a hybrid space that merges the physical and the digital, the formal with the informal, and increasingly shares responsibility between the educator and the empowered learner. Digital resource providers can engage in new ways with users changing the ways in which resources are used and valued. However the rules and behaviours of e-learning and online social spaces are still (and likely will remain) in flux with privacy concerns and the potential for bullying both important as social media spaces are brought into the e-learning process (Davis \& Lee 2008; Keashly \& Neuman 2010).

The combination of approach, educational style(s) and technologies employed can shape the needs or expectations of 
the e-learner. For instance flexible e-learning courses can fit well with learner-centric pedagogical approaches (and deal well with the fact that each learner accesses their course in highly individual contexts) but can present particular challenges for those who thrive in a highly ordered structured space. There is not one single format, structure or type of e-learning experience, instead it is a continuum and tools including VLEs and specialist DL resources may be employed in radically different ways.

These changes and technologies offer huge potential for enriched and engaged learning experiences but each new technology creates new challenges and further diversifies the needs and expectations of both educational professionals and learners (e.g. Dutton, Cheong and Park 2004, Eynon 2005, Woods, Baker and Hopper 2004).

\section{Popular uses of digital resources in learning}

\section{Beyond the library walls}

Perhaps the most mainstream digital resources for learning are electronic journals which have rapidly become ubiquitous thanks to their searchability, accessibility and their connectivity to additional materials such as referenced materials, videos or full colour imagery. Increasingly articles also connect to original data and are moving away from print counterparts to become transliterate (Thomas et al 2007) experiences: objects that weave text, audio, video, interactive models, dynamic visualisations, and actively updated discussion and reflection on the central academic object.

As electronic journals and e-books have emerged online the process of reading and interpreting a journal article need no longer be a solitary experience with online citation and ratings toolsii (e.g. Mendeleyiii), social bookmarking (e.g. deliciousiv, Evernotev) and annotation tools (e.g. A.nnotatevi, diigovii, Google SideWikiviii), along with discussion spaces and instant messaging, adopted as tools for collective reading. One can share thoughts in real time or asynchronously with fellow learners whether they are within institutional walls or outside of them. Indeed the openness of current digital environments for learning can be highly complex: learning may be enriched by serendipitous contact with interested outsiders however licensed content is usually tied to institutions and it can be highly challenging for educators to remain active and aware of the diverse formal and informal learning spaces their students may use. Indeed the interplay between officially approved or recommended academic tools and commercial web tools (both specialist and non specialist) reflects the ongoing tension between the forces that push at change in learning more widely: what the educators and/or institutions promote or want learners to use versus what learners 
want to use, or in some cases, find easier to use.

\section{Finding, tracking, and sharing electronic resources}

The tools and websites that manage access to electronic resources have also become increasingly sophisticated moving beyond portals and traditional OPACs and catalogue-like interfaces, to federated searches, iGoogleix and Facebookx widgetsxi and mobile phone appsxii and sophisticated discovery tools which connect distributed web services "mashed up" with local resourcesxiii. The user experience has moved from traditional search and/or browse interfaces to those which promote serendipitous discovery through faceted search, tag clouds, etc.

\section{Connecting electronic resources to teaching and learning}

These sit alongside (and in some cases are embedded into) VLEs such as WebCT/Blackboardxiv, SAKAlxv, Moodlexvi, or Elggxvii or Ningxviii in which course notes and DL tools and resources and active class discussion spaces coexist. These resources support and are supported by in-person teaching, tutorials, guidance etc.

Whilst the delivery of pure e-learning is still a relatively niche practicexix this type of hybrid learning experience is commonplace with students accessing course materials online and using digital devices as part of the learning process whether laptops at lectures or checking course materials via mobile phonesxx (for the specifics of mobile devices see Chapter $\mathrm{xx}$ ). Group work is as likely to involve students or colleagues gathering around a computer or smartboard and taking part in a digital and/or online project as to be about working around a flip chart or whiteboard. With mainstream education embracing the $\mathrm{DL}$ and online world it is hardly surprising that learning activities have merged into informal spaces, including social media, gaming environments (e.g. Prensky 2001, Gee 2003, Whitton 2010), that learners are already familiar with. However the move to both formal support for learners and informal peer support in digital spaces can risk alienating learners with little experience or confidence with computers or the internet, or those with weaker social connections to their peers.

\section{Beyond the (virtual) institutional walls}

When learning communities expand in irregular patterns into informal, often commercially operated spaces they transgress the boundaries and control of the academy, opening up potential inequalities for learners, and greater potential for the circulation of information (and misinformation). The concept of scaffolding students (supporting, encouraging, and occasionally pushing for correction by more experienced peers or teachers) as they reach the 
bounds of their skill levels (Vygotsky 1978) is an important part of the learning process in physical learning spaces but in wilder online spaces there may be an absence or subversion (through poor/ill informed support) of such scaffolding. However this blurring provides huge opportunities for cross-organisational, interdisciplinary and serendipitous connection and reflection. In addition participation in learning practices in informal, playful, social online spaces can feel far more intrinsically motivating than traditional learning experiences.

An excellent example of the intersection of informal learning, social media and traditional entertainment, has been the phenomenal success of TED (TED Conferences LLC 2011) lectures online. These short talks, often presented by academics and expert thinkers, elicit blockbusting viewing levels and viral sharing through social media sites. Although the presentation styles of these videos are informal, catchy and brief there is additional appeal in these being artefacts and experiences discovered and shared/curated by the (informal) learner.

\section{Future challenges}

The challenge for traditional educational institutions, DLs and educational resource providers is therefore to move away from being driven by technical solutions and instead consider how best to create more relevant and engaging user experiences. The recent JISC UX2 project addressed such concerns by looking at the needs of library users and exploring various approaches and technologies to improve the user experience for academic library catalogues (see Paterson and Low 2010).

To some extent it can be assumed that commercial websites offer user experiences that appeal to self-directed learners as they often encourages a sense of playfulness and openness. However many learners and teaching staff are experienced and comfortable with existing academic tools and those with more formal structures and significant help and support information. Many user interfaces currently rely on technologies which are not accessible to learners requiring accessibility technologies to interpret websites and resources. Equality of access to resources, particularly as learning and library materials generally move online, presents particular challenges for digital resource providers in the development, design or procurement of tools and interfaces.

The intuitive user experience of non-academic websites and tools can also be problematic in establishing good information seeking behaviours in learners. It is therefore increasingly important to engage with these resources, to train learners to differentiate between resources and to emphasize, as appropriate, the authenticity and authority of 
data or resources provided by institutional or trusted digital resource providers.

In the following example I will reflect on experiences of combining digital resources with social media in order to foster an engaged community and craft a more appealing and accessible online offering. The example will look at the way in which social media raised awareness of the UKOERxxi initiative and how this has connected to the social media and community building activities, and reuse of digital materials, for the Jorum Servicexxii.

\section{Example: Jorum and OER}

Jorumxxiii is a free online repository for the Higher Education and Further Education sectors in the UK. Jorum is funded by JISC and operated by Mimasxxiv, having been jointly developed with EDINAxxv. The service began as a cutting edge project to create a repository for teaching and learning materials to preserve the outputs of JISC-funded projects and complimentary materials such as those created for the National Learning Network (Halliday 2008). Most of these contributed materials were licensed by their creators for viewing, use and reuse within the UK or within their own institution.

Jorum appeared at a time of increased use of digital resources and VLEs to support traditional and e-learning courses but a culture of sharing and reusing materials was only just emerging. In 2008 work began on JorumOpen, a version of Jorum to allow the upload of materials for broader sharing under creative commons licences. In particular JorumOpen was established as the mandated deposit space for materials created under the Open Educational Resources Programme (OER) funding calls from JISC and the Higher Education Academy (JISC 2010).

The Open Educational Resources concept is a worldwide movement to encourage the culture and practice of sharing learning materials. There are large and well established communities around OER, particularly in the United States, and these communities often provide support and advice through social media sites, for instance there is a particularly strong thread of discussion and support via Twitter on OER. These presences also represent the types of blending and blurring that takes place between institutional learning objects in the VLE with openly shared educational resources (from colleagues, other institutions, etc), and with publicly shared materials perhaps not created with any pedagogical purpose in mind (YouTube videos for instance). This existing community activity presented a superb opportunity for raising the profile of JorumOpen and engaging with creators and users of OER materials. A Twitter accountxxvi allowed participation in the \#OERxxvii and \#UKOERxxviii conversations on Twitter; a Facebook presencexxix enabled 
engagement with teaching staff using Facebook for teaching and professional networking; sharing functionality within JorumOpen has enabled bookmarking and sharing of content to raise it's profile and that of the site; and the long standing Jorum blogxxx was complimented with videos about OER and JorumOpen as well as highlighting best practice.

One of the most successful methods for raising the profile of digital learning materials within JorumOpen and for encouraging best practice in the creation, use and/or reuse of these materials has been the Jorum Learning and Teaching Competitionxxxi which has been awarded at the ALT-C Conferencexxxii in both 2009 and 2010. Creators of learning materials were asked to submit their work and, as this was already openly shared, the links to entered, shortlisted and winning materials could be shared via blog posts, tweets, etc. This helped identify the range of materials in JorumOpen and demonstrate the ways in which educators are combining their own learning resources with existing materials (such as images and video) and feeding this into pedagogically driven websites or resources for use in their VLEs. This opportunity to focus on the content rather than Jorum/JorumOpen as a tool has been a superb approach for engaging teaching staff across the UK (and beyond) in the resources and ideas behind OER and the use of learning material repositories in general. Activity around the competition starts conversations about OER, about specific learning materials as well as general issues in this space, and encourages sharing of further materials.

The nature of the OER community is such that individuals and institutions tend to be proactively engaged in the use of technology and, as they have elected to become involved in the programme, the notion of sharing and discussions that take place in public online spaces. It is important to note that this is perhaps not typical of the broader digital library or academic community though there are active online communities around both interest areas.

Some of the most active discussions around OER are also not those on best practice but differing stand points on hot topics for the community, such as which creative commons are sufficiently open for an ideal culture of sharing and reuse. This raises a challenge for anyone hoping to engage and learn from their users: it is far easier to trigger activity, comment, feedback, advocacy, and to learn directly about the needs of users when they are excited or excised about an issue but far harder to engage individuals around less controversial topics. For instance whilst the JorumOpen OER experience has provided a wealth of rich conversations on licensing it has not yielded as much community generated discussion on the most effective pedagogical approaches around creating or using digital resources. This has been addressed through collection and publicising of best practice and case studies however the underlying tension 
between engaging on topics of self-interest versus less fiercely debated topics that could contribute significantly to understanding and serving users will be familiar from many other contexts within and beyond the academic sector.

\section{Conclusions}

The increasing use of digital resources in the academic sector brings many opportunities and challenges which are amplified by the ubiquity of engagement in online learning and social media spaces.

Historically much of the interest in developing digital tools and resources has focused on the technical: what is technically possible and what is desirable for funders or policy makers. It is important, as the technology is maturing, to reflect on the role that user needs have and could play in future developments. Taking this approach in academic settings very much reflects similar shifts in the commercial sector where "Web 2.0" tools have very much been about the shift from more rigid sites and services created by commercial providers over long periods of time towards rapidly developed user centred services and sites that retain users more through user experience than data lock-in or subscription terms.

Authenticity, authority and trustworthiness have greater importance for users online where traditional marks of authenticity (inclusion in a physical collection, publisher, even crude tools for judging quality such as cover design) may not be available and where a wealth of competing resources are present. However the vast array of materials also increases the potential for flexible and accessible routes to learning. If a recommended resource is difficult for a user to access perhaps there is another related item - a review of a paper, a video about it, a comment by the author - that will enable a richer understanding.

Individuals (student or teaching staff) need no longer rely on colleagues and peers for support, correction and gentle scaffolding as the online learning space empowers them to discover and access materials, support and peers working across the globe. Though discourses on the democratising nature of the internet can be rather hyperbolic it is undeniable that digital resources of all kinds are enabling enhanced access to information and a new appreciation of the ongoing nature of learning whether highly structured or very informal in form. 


\section{References}

Brown, J. S. (2005). New Learning Environments for the 21 Century. Forum for the Future of Higher Education Symposium. Aspen.

Davis, M and Lee, B. (2008). The legal implications of student use of social networking sites in the UK and US: current concernsa dn lessons for the future. In Education \& the Law 20 (3). pp. 259-288.

de Freitas, S. (2008) Emerging Technologies for Learning. BECTA research report, March 2008, Volume 3 (2008).

Dutton, W.H., Cheong, P.H. and Park, A. (2004). An Ecology of Constraints on e-Learning in Higher Education: The Case of a Virtual Learning Environment. Prometheus, 22 (2). Pp. 131-149. Retrieved $5^{\text {th }}$ April 2011.

http://dx.doi.org/http://dx.doi.org/10.1080/0810902042000218337/

Dutton, W.H., Helsper, E. J. and Gerber, M. M. (2009). The Internet in Britain: 2009. Oxford Internet Institute, University of Oxford. Retrieved $5^{\text {th }}$ April 2011. http://www.oii.ox.ac.uk/research/oxis/OxIS2009_Report.pdf.

Edwards, R. (2006) A Sticky Business? Exploring the "and" in Teaching and Learning. In Discourse: studies in the cultural politics of education, 27 (1). pp. 121-133. $5^{\text {th }}$ April 2011. http://dx.doi.org/10.1080/01596300500510336

Eynon, R. (2005). The use of the internet in higher education: Academics' experiences of using ICTs for teaching and learning. In Aslib Proceedings: new information perspectives, 57 (2). Pp. 168-180(13). Retrieved $5^{\text {th }}$ April 2011. http://dx.doi.org/10.1108/00012530510589137/

Gee, J. P. (2003). What video games have to teach us about learning and literacy, New York: Palgrave Macmillan.

Halliday, L. (2008). A History of Jorum, the Learning Resource Repository for UK Higher and Further Education (20022008). Jorum website. Retrieved $5^{\text {th }}$ April 2011. http://jorum.ac.uk/about-us/history.

Ito, M. (2010). Peer-Based Learning in a Networked Age. Keynote address for University of Michigan's Enriching Scholarship 2010. Retrieved $5^{\text {th }}$ April 2011. http://www.itofisher.com/mito/publications/peerbased_learn_2.html

Jackson, Janna (2009). Game-based teaching: what educators can learn from video games. Teaching Education, 20 (3). pp. 291 - 304. Retrieved $10^{\text {th }}$ April 2010. http://dx.doi.org/10.1080/10476210902912533

JISC (2010). Open educational resources programme - phase 1. JISC Website. Retrieved $5^{\text {th }}$ April 2011. http://www.jisc.ac.uk/whatwedo/programmes/elearning/oer.aspx.

Keashly, L and Neuman, J. (2010). Faculty experiences with bullying in Higher Education. In Administrative Theory \& Praxis 32 (1). pp. 48-70.

Lave, J. and Wenger, E. (1991). Situated learning . Cambridge, England: Cambridge University Press.

Lenhart, A., Purcell, K., Smith, A and Zickuhr, K. (2010). Social media \& mobile internet use amongst teens and young adults. Pew Internet and American Life Project. Retrieved $5^{\text {th }}$ April 2011. http://pewinternet.org/Reports/2010/SocialMedia-and-Young-Adults.aspx.

Paterson, Lorraine and Low, Boon (2010). Usability Inspection of Digital Libraries. In Ariadne (63). Retrieved $3^{\text {rd }}$ March 2011. http://www.ariadne.ac.uk/issue63/paterson-low/.

Prensky, Marc (2001). Digital Game-based Learning. (USA: McGraw-Hill)

Ross, J., Bayne, S., Macleod, H., O'Shea, C. (2011). Introducing a manifesto for teaching online . Presentation at the University of Edinburgh e-Learning@Ed event held on Friday $1^{\text {st }}$ April 2011 at the National eScience Centre, Edinburgh.

TED Conferences LLC (2011). TED: Ideas worth sharing [website]. Accessed $2^{\text {nd }}$ March 2011. http://www.ted.com/

Thomas, S et al (2007) Transliteracy: crossing divides. First Monday. 12(12). [web site] 
Vygotsky, L. (1978). Mind in Society: The Development of Higher Psychological Functions. Cambridge, MA: Harvard University Press.

Whitton, N. (2010). Learning with Digital Games: A practical guide to engaging students in higher education, London: Routledge.

Woods, R., Baker, J. D. and Hopper, D. (2004). Hybrid structures: Faculty use and perception of web-based courseware as a supplement to face-to-face instruction. The Internet and Higher Education, 7 (4). Pp. 281-297. Retrieved $5^{\text {th }}$ April 2011. http://dx.doi.org/10.1016/j.iheduc.2004.09.002.

i Nearly half of all respondents to the 2009 Oxford Internet Survey reported having created a profile on a social networking site (Dutton, Helsper, and Gerber 2009) and this looks likely to rise: the Pew Internet and American Life Project found that $73 \%$ of American teenagers used social networking sites (Lenhart, Purcell, Smith and Zickuhr 2010).

ii These tools are used for recording, aggregating and sharing citations for academic reading, assignments, publications etc. Some allow ratings and comments to be added to citations.

iii Mendeley, <http://mendeley.com/> is a web and downloadable tool for tracking academic reading and citations. These can be shared and recommendations for further reading received via an integrated social networking site.

iv Delicious, http://delicious.com/, is a social bookmarking tool enableing sharing of URLs/bookmarks and notes across machines. Bookmarks can also be shared with other users or via public profiles and RSS feeds.

V Evernote, http://www.evernote.com/, is a social bookmarking tool that works like a virtual scrapbook of resources allowing text, URLs, images, video, etc. to be shared online.

vi A.nnotate, http://a.notate.com/, allows online annotation of a document by one or multiple participants.

vii Diigo, <http://www.diigo.com/>, is a social bookmarking tool that allows users to share notes on websites via a browser plugin which shows mini virtual sticky notes within a webpage - for instance a particular paragraph or image may be commented upon and shared with all, or selected, users.

viiiGoogle Sidewiki, http://www.google.com/sidewiki/, like Diigo, allows users to make comments on websites via a browser plugin. Notes appear in a sidebar which can be expanded to read or comment on the current page.

ix iGoogle is a personalised version of google.com. The page can be customised with widgets (search, countdowns to events, games, etc.), RSS feeds, and similar tools to create a personal start page alongside the familiar Google search box.

$\mathrm{X}$ Facebook is the most widely used (in the UK and US) social networking site at the time of writing, http://www.facebook.com/.

Xi Widgets are tools allowing content from one website or data source to be embedded in another. Widgets are usually a simple Javascript presentation of data retrieved automatically over the internet. Library related widgets include the SUNCAT (Serials Union Catalogue for the UK, http://www.suncat.ac.uk/), iGoogle gadget or Facebook application, the Copac (http://www.copac.ac.uk/), and Worldcat (http://www.worldcat.org/) catalogue search widgets.

xii For instance commercial organisations such as OMBIEL are developing mobile applications which universities can customise as applications for members of their institution to include library searches, campus maps, etc.

xiiiMash ups tend to be combinations of multiple electronic resources, often through creating a user facing combination of information drawn from RSS feeds, APIs (Application Programming Interfaces) and similar information. For example Dave Pattern's work to combine the University of Huddersfield catalogue with book jackets from Amazon, borrowing statistics, related materials etc. is a good example of mashed up library resources. See, for instance, the presentation "Web 2.0 in action: experiences from the University of Huddersfield", http://eprints.hud.ac.uk/9629/.

xiv WebCT or Blackboard (previously two products now combined) is a virtual learning environment which allows sharing of learning materials such as lecture notes, videos, etc. as well as assignment submission, discussion boards and similar functionality. The environment is structured and may either allow access for materials to be downloaded or be presented as html pages/course materials linking to materials both within and outside the environment.

XV SAKAI is an open source virtual learning environment developed by the academic community to allow similar sharing and administrative tools as WebCT or Blackboard.

$\mathrm{XVi} \quad$ Moodle is an open source virtual learning environment designed for similar course material sharing as WebCT or Blackboard.

XVii Elgg is an open source social networking tool used in a number of academic organisations as a space for sharing course notes, blogs and course discussions.

XViii Ning is a commercial social networking tool which can be used as a restricted space for sharing course materials, learner blogs and discussions.

xix This is partly a consequence of the fact that e-learning is still a very recent practice in comparison to traditional teaching formats. e-learning has often been associated with questionable and/or unregulated "qualifications by post" 
schemes so there is also a significant cultural barrier that must be overcome by institutions adopting e-learning fully for courses though the Open University and the University of Edinburgh MSc in eLearning programme are both exemplars of good practice in delivering high quality and well respected fully online courses.

XX Mobile is an increasingly important space, particularly in academia, for example see the 2010 University of

Edinburgh Mobile Survey,

http://www.projects.ed.ac.uk/areas/itservices/integrated/ITS045/Other_documents/MobileSurvey2010.shtml and the findings of the 2011 Horizon report, http://www.nmc.org/publications/2011-horizon-report.

XXi More information on the UK OER programme can be found on the JISC website,

http://www.jisc.ac.uk/whatwedo/programmes/elearning/oer.aspx.

XXii Jorum and Jorum Open, http://www.jorum.ac.uk/.

XXiii Jorum, JorumOpen and related social media presences can be accessed at http://jorum.ac.uk/

XXiV Mimas is a JISC designated National Data Centre based at the University of Manchester, http://mimas.ac.uk/.

XXV EDINA is a JISC designated National Data Centre based at the University of Edinburgh, http://edina.ac.uk/.

XXVi The Jorum Twitter account can be accessed at http://www.twitter.com/jorumteam.

XXVii \#OER is the hashtag that the Twitter community most frequently uses for discussion of Open Educational Resources.

XXViii \#UKOER (or \#ukoer) is the officially recommended hashtag for use by the Twitter community in discussions of the UK OER programme.

xxix The Jorum Facebook page can be accessed at http://www.facebook.com/JorumTeam/.

XXX The Jorum blog was located at http://jorumnews.blogspot.com/, since summer 2011 the blog has migrated to http://www.jorum.ac.uk/blog.

XXXi Information on the 2010 competition can be found on the Jorum website, http://www.jorum.ac.uk/altccompetition2010.

XXXii ALT-C, http://www.alt.ac.uk/, is the annual conference for Association for Learning Technology. 